\title{
Improving Performance Loan Fraud Model Prediction Using Mean Decrease Accuracy and Mean Decrease Gini
}

\author{
Arsandi Akhmad ${ }^{1}$ Lukas $^{1}$ and Bagus Mahawan ${ }^{1}$ \\ ${ }^{1}$ Department of Information Technology, Swiss German University, Tangerang \\ 15143 , Indonesia
}

\begin{abstract}
The purpose of this research is to develop a fraud detection model on loan transactions at failed banks in the context of deposit and deposit guarantees mandated to the Indonesia Deposit Insurance Corporation (IDIC). The data used in this study is the data of a bank in the Jakarta area that had liquidated at the end of 2015. Meanwhile, data on loan transaction ranges ranged from 2010 to 2015. This research also focuses on improving the performance of detection models by using feature selection. With the feature selection, it expected that the impact of the reduced performance of the model exposed to high variance and high bias due to the many features used can handled better.
\end{abstract}

\section{Introduction}

\subsection{Background}

Banks are business entities that collect funds from the public in the form of deposits and channel them to the public in the form of loans and/ or other forms in order to improve the lives of many people (Indonesia, 1998). Banking provides various types of alternative loan funds for customers, one of which is through providing loans in the form of loans to customers. Indeed, in granting credit to customers, the bank experiences various problems or risks. One of the problems or risks experienced by banks in granting credit is the behaviour of customers who do not pay instalments on time or delay up to several months in instalment payments which ultimately causes bad credit rating. This is a serious problem that needs to be considered by the bank because the regulator determines the maximum percentage of NonPerforming Loans (NPL) (Kustina, 2018). If the level is above the set limit, the bank is declared as special handling status.

Therefore, some banks in special handling status and experience normal liquidity difficulties commit fraudulent financial records to keep NPL levels low. One method that is commonly used is to do window dressing transactions that are usually if related to credit; there will be transactions that are not supposed to be like the existence of credit instalment payment transactions without accompanied by the actual flow of funds. When the bank's condition gets worse so it must be liquidated, the fraudulent action causes the under-stated loan balance, and credit quality is not a real condition. The impact is that in the process of guaranteeing customers' funds, it will lead to wrong decision making regarding guaranteed customer funds.

To be more careful in determining customer funding guarantees, there is a need for a calculation method with an intelligent computing system to assist the Indonesia Deposit Insurance Corporation (IDIC) in selecting which customers are eligible to pay. The methods used can be Regression Analysis, Neural Networks, Genetic Algorithms, Decision Tree, and Random Forest.

\subsection{Random Forest}

The Random Forest was first officially published by Leo Breiman in 2001 (Breiman, 2001). The Random Forest was developed to improve Decision Tree methods that are prone to overfitting. In its development, Random Forest has become one of the popular methods in the field of machine learning. This is due to the ease of use of Random Forest, which is capable of achieving high accuracy without the need to do many tuning parameters.

The Random Forest learning process uses the CART (Classification and Regression Tree) method. CART is a non-parametric method that is useful for getting a group of accurate data as a characteristic of a classification. The CART classification method consists of two methods, namely the regression tree method and the classification tree. If the dependent variable has a specific type, then CART produces 
classification trees. Whereas if the dependent variable is of a continuous or numerical type, CART produces regression trees (Breiman, 1996).

\subsection{Related Work}

Detection of fraudulent financial statement can be done in various ways, and many studies have been conducted related to this. The most commonly used method is to use the concept of the Fraud Triangle when analysing documents in the audit process that is done in a worksheet and looking at the pattern of fraud (Huda et al., 2014). The study of transactional fraud especially related to financing is usually carried out by examining entities or variables from credit data such as jobs, homeownership, collateral, number of dependents and others (Xu et al., 2016). Also, a study of credit financing fraud can be done using detailed transaction data such as fraud on credit cards. Choi et al. (Choi et al., 2013) In their study developed an individual level utility concept which would later be used to evaluate the model. The study conducted by Johannson et al. (Jóhannsson, 2017) uses transaction behaviour profiling and performs time analysis of transaction data and makes variables used in the detection model.

The problem that is often faced in building fraud detection models is the number of features used in the dataset so that the prediction model becomes biased, and the model's performance decrease. Several studies have been done to reduce bias and improve performance in detection models such as Hong Han et al. (Hong Han et al., 2016) makes a study to reduce the error rate by making feature selection using the Mean Decrease Gini and Mean Decreasing Accuracy where iterates the feature reduction with that method. Hasan et al. (Hasan, 2017) also made a study of how to improve accuracy by making feature selection using Forward / Stepwise Regression implemented in prediction models based on SVM. Improving performance model also can be done by calibrating the probability values used in the prediction model. Alejandro Bahnsen (Bahnsen et al., 2014) study about calibrates probability values that will be used in the ROC curve to improve the performance of the model. Louppe et al. (Louppe et al., 2013) conducted a study of the dataset feature by calculating the mean deviation impurity (MDI) score that can be used to select features.

\section{Materials and Methods}

The data to be used in this study are from the XYZ Rural Bank, located in Tangerang. The number of datasets to be used in this study is 6448 records. Loan data used as a basis for predicting loan fraud is obtained when Bank XYZ is liquidated by IDIC and also records of which credit fraud perpetrators are banned without the flow of funds. Variables used in predicting credit risk in this study consist of 12 input variables and one target variable, namely:

Table 1. List of features in the dataset and its description

\begin{tabular}{|c|c|}
\hline Feature & Description \\
\hline $\mathrm{Sb}$ & Loan Interest rate \\
\hline Plafond & Loan Amount \\
\hline PLF & $\begin{array}{l}\text { Features created with the criteria if the new loan is realised in the range } \\
\text { of } 30 \text { days before up to } 30 \text { days after the previous credit is repaid. If yes } \\
\text { value }=1 \text { and if no value }=0\end{array}$ \\
\hline PLF1 & $\begin{array}{l}\text { The Comparison between the new amount of loan and the previous } \\
\text { amount of loan. If new loan higher than the previous loan, the value will } \\
\text { be set as } 1 \text { and if not, the value will be set as } 0\end{array}$ \\
\hline PLF2 & $\begin{array}{l}\text { the Features created with criteria if another loan was realised less than } \\
\text { one year from the previous realisation loan. }\end{array}$ \\
\hline PLF3 & $\begin{array}{l}\text { Feature created as a flag if repaid date greater than } 60 \text { days from its } \\
\text { schedule }\end{array}$ \\
\hline PLF4 & closing date in month/ divide total month in the schedule \\
\hline $\mathrm{Col} 2$ & $\begin{array}{l}\text { sum transaction that days between two transactions is between } 90 \text { until } \\
180 \text { days }\end{array}$ \\
\hline Col3 & $\begin{array}{l}\text { sum transaction that days between two transactions is between } 180 \text { until } \\
360 \text { days }\end{array}$ \\
\hline Col4 & sum transaction that days between two transactions are greater 360 days \\
\hline
\end{tabular}




\begin{tabular}{ll}
\hline Feature & Description \\
\hline Rata-rata.Jarak.Angs & averages of days between two instalments transaction \\
Tunggakan & is any arrears in instalment transaction \\
dialling & instalment payments are bailed out (fraud flag) \\
\hline
\end{tabular}

Framework in this study follow CRISP-DM (Chongwatpol et al., 2012)that contains the life cycle of six-phase data mining activities, but in this study follow until the fifth phase. One of the advantages of this model is that the phase stages of the model are not a rigid stage. Moving forward and backwards between each different phase can always be done. This is by the nature of data mining, where the data mining process is not completed when a result is found because the process of data mining is a continuous learning process continuously. The experimental design model can be explained in several stages:

1. Collection of credit customer datasets where customer credit datasets was collected at XYZ bank, which amounts to 6448 records.

2. Distribution of the dataset will be divided into two parts, namely, data transfer and testing data. Data sharing will be carried out stratified.

3. Applying the Random Forest Algorithm after data sharing, training data will be processed to obtain the prediction model.

4. Evaluate prediction models using data testing by looking for measurement values of models such as Accuracy, Kappa, Specificity and Sensitivity.

5. Using Mean Decrease Accuracy - Mean Decrease Gini as a Featured method Selection and chose the top ten scores then create a new dataset.

6. It is creating a Random Forest model based on data that has been reduced by the variable and validating it using the testing data.

7. Compare the performance of the non-feature selection and feature selection models.

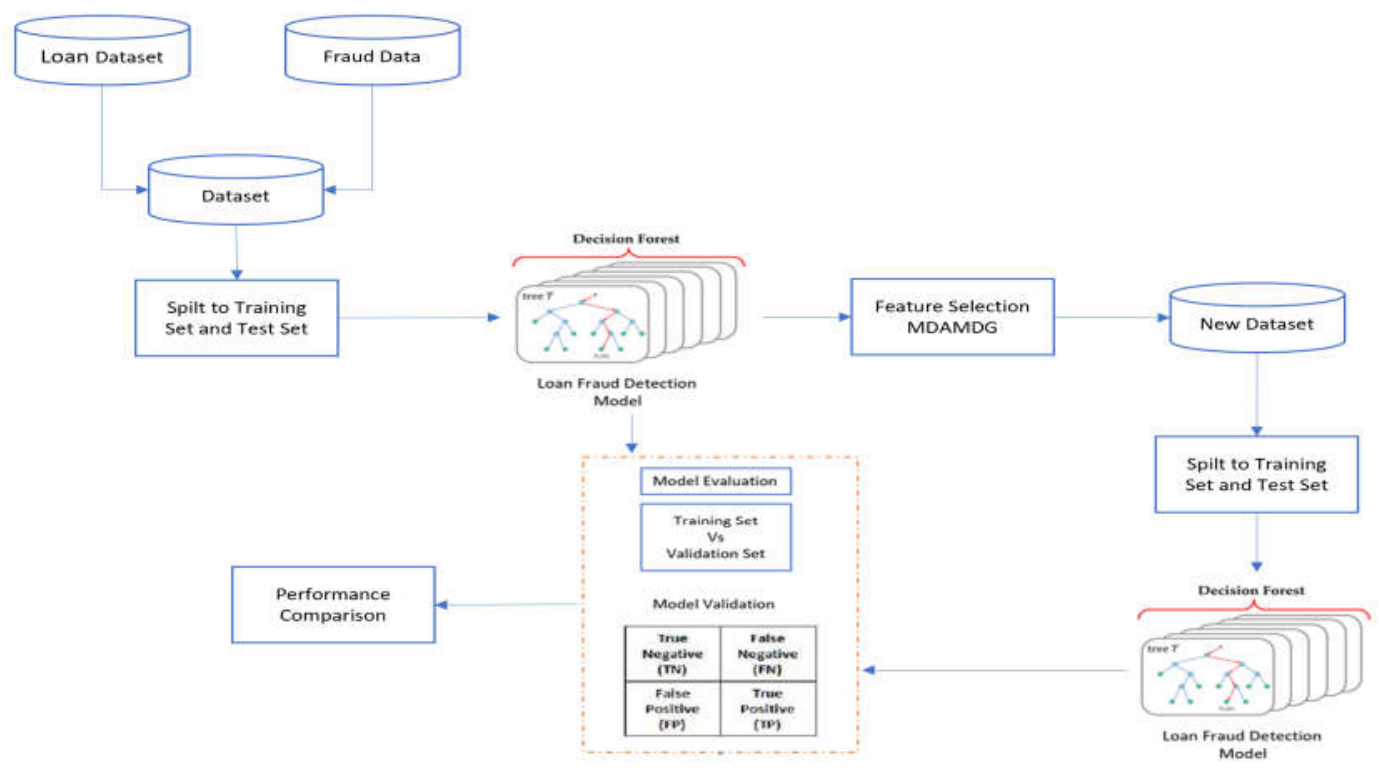

Figure 1. Research Framework

\section{Results and Discussion}

The test and the experiment were conducted using R 3.6.1 for Windows OS version. Test and experiment where conducted base upon:

a. Bank Loan dataset without using feature selection

b. Tuning the model and analyse variable using Mean Decrease Accuracy and Mean Decrease Gini as Feature Selection than create a new dataset. 
c. Bank Loan dataset with feature selection.

Each dataset was applied to Random Forest Algorithm to create a classification model. To get the minimum out-of-bag error, tuning classification needed for every model.

\subsection{Feature Selection.}

To obtain the calculation score of Mean Decrease Accuracy (MDA) and Mean Decrease Gini (MDG), the Random Forest package can use the importance function and visualise it can use the varImPlot function. The value of Mean Decrease Accuracy and Mean Decrease Gini scores are shown in Table 2 and already ordered from the largest and smallest. From Table 2 can be seen features sb, plafond, PLF2 dan Rata-rata.Jarak.Angs as the most important feature. In Random Forest, Gini impurity affects the impurity of the data so that if the feature with the MDG value omitted, the data will be increasingly difficult to classify. Likewise, with the MDA value, which if the feature with the highest value omitted, the value of accuracy will be decreased. For better performance model, feature with the highest score in the dataset is selected by using Mean Decrease Accuracy and Mean Decrease Gini. While for the MDA and MDG values that are small, the feature is not too influential or even causes a bias in the model.

Table 2. Mean Decrease Accuracy and Mean Decrease Gini Score

\begin{tabular}{lrr}
\hline \multicolumn{1}{c}{ Variable } & MeanDecreaseAccuracy & MeanDecreaseGini \\
\hline sb & 164.21330 & 961.47057 \\
plafond & 87.13234 & 366.61910 \\
PLF & 11.42071 & 15.00216 \\
PLF1 & 18.22853 & 22.04726 \\
PLF2 & 84.62336 & 277.34986 \\
PLF3 & 16.80891 & 18.38644 \\
PLF4 & 59.63332 & 232.29434 \\
Col2 & 37.97315 & 141.87118 \\
Col3 & 25.24739 & 39.97915 \\
Col4 & 28.34939 & 77.40978 \\
Rata-rata.Jarak.Angs & 73.80904 & 297.08782 \\
\hline
\end{tabular}

\subsection{Performance Metrics}

This study uses the statistical measurement for performance model test that conducted. The statistical measure includes accuracy, Kappa, sensitivity, specificity, true-positive rate, false-positive rate and Pvalue. In Tables 2 and 3, there is a comparison of the value of performance statistics between non-feature selection and feature selection. If we look further, there is an increase in the value of accuracy from 0.7395 to 0.7599 . Also there is an increase in the value of Cohen's Kappa from 0.4168 to 0.4348 , which indicates an increase in the degree of agreement. The sensitivity (True Positive Rate) value increases from 08006 to 0.8658 , which indicates that the detection rate for fraud class increases even though the Specific Negative Rate decreases from 0.6178 to 0.5492 . 
Table 3. Performance measure comparison between non-feature selection and feature selection

\begin{tabular}{lrr}
\hline Measurement & Before Feature Selection & After Feature Selection \\
\hline Accuracy & 0.7395 & 0.7599 \\
95\% CI & $(0.7173,0.7607)$ & $(0.7383,0.7806)$ \\
P-Value [Acc > NIR] & $8.47 \mathrm{E}-11$ & $<2.2 \mathrm{e}-16$ \\
Kappa & 0.4168 & 0.4348 \\
Mcnemar's Test P- & 0.7327 & $6.31 \mathrm{E}-07$ \\
Value & & \\
Sensitivity & 0.8006 & 0.8658 \\
Specificity & 0.6178 & 0.5492 \\
Pos Pred Value & 0.8066 & 0.7927 \\
Neg Pred Value & 0.6088 & 0.6727 \\
Prevalence & 0.6656 & 0.6656 \\
Detection Rate & 0.5329 & 0.5763 \\
Detection Prevalence & 0.6607 & 0.7270 \\
Balanced Accuracy & 0.7092 & 0.7075 \\
\hline
\end{tabular}

The performance of the prediction model can also be measured using the ROC curve and the AUC value. In Figure 2, it can be seen that the AUC value of the non-feature selection model is 0.7980399 , and the model with the selected feature is 0.7988154 . There is an increase in value even though it is not too significant so that the ROC curve between the two models is not too different in shape.

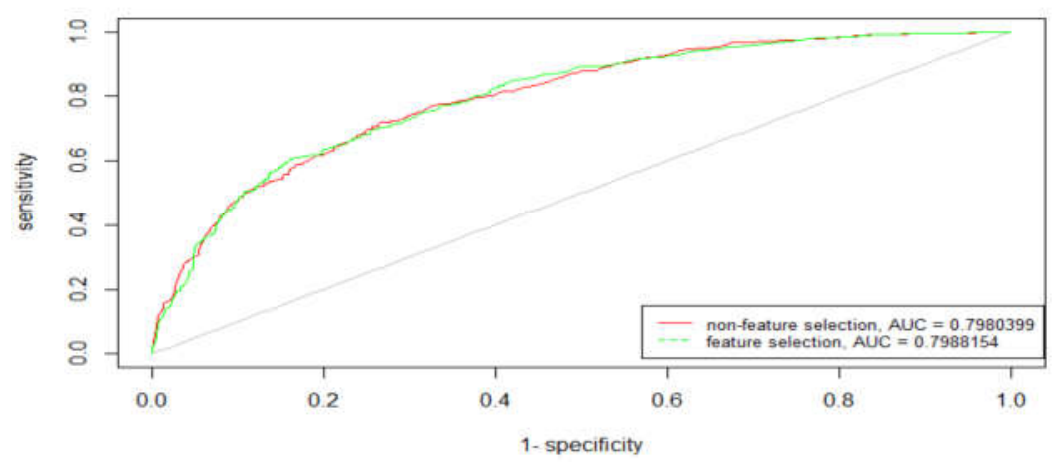

Figure 2. ROC curve non-feature selection and feature selection model

\section{Conclusion}

In this paper, a fraud prediction study in credit instalment payment transactions can be done using the Random Forest algorithm and from the results of experiments and tests that predict the model can predict credit fraud is good enough it can be seen from the accuracy value of 0.7395 and some statistical values of model performance measurement. In addition to improving performance, a feature selection is performed by using Mean Decrease Accuracy and Mean Decrease Gini where the results of the prediction model by reducing the less important features have an impact on increasing the accuracy value to 0.7599 and several other performance measurement values. We hope that further research can improve the performance of the detection model even better.

\section{References}

Bahnsen, A.C., Stojanovic, A., Aouada, D., Ottersten, B., 2014. Improving Credit Card Fraud Detection with Calibrated Probabilities, in: Proceedings of the 2014 SIAM International Conference on Data Mining. Presented at the Proceedings of the 2014 SIAM International Conference on Data 
Mining, Society for Industrial and Applied Mathematics, pp. 677-685. https://doi.org/10.1137/1.9781611973440.78

Breiman, L., 2001. Random forests. Mach. Learn. 45, 5-32.

Breiman, L., 1996. Bagging predictors. Mach. Learn. 24, 123-140.

Choi, K., Kim, G., Suh, Y., 2013. Classification model for detecting and managing credit loan fraud based on individual-level utility concept. ACM SIGMIS Database 44, 49. https://doi.org/10.1145/2516955.2516959

Chongwatpol, J., Sa-ngasoongsong, A., Woratanarat, P., Sa-ngasoongsong, P., 2012. Prognostic Analysis of Hip Fracture in Elderly Women with Data Mining Methods 11.

Hasan, M., 2017. PREDIKSI TINGKAT KELANCARAN PEMBAYARAN KREDIT BANK MENGGUNAKAN ALGORITMA NAÏVE BAYES BERBASIS FORWARD SELECTION. Ilk. J. Ilm. 9, 317. https://doi.org/10.33096/ilkom.v9i3.163.317-324

Hong Han, Xiaoling Guo, Hua Yu, 2016. Variable selection using Mean Decrease Accuracy and Mean Decrease Gini based on Random Forest, in: 2016 7th IEEE International Conference on Software Engineering and Service Science (ICSESS). Presented at the 2016 7th IEEE International Conference on Software Engineering and Service Science (ICSESS), IEEE, Beijing, China, pp. 219-224. https://doi.org/10.1109/ICSESS.2016.7883053

Huda, S., Ahmad, T., Sarno, R., Santoso, H.A., 2014. Identification of process-based fraud patterns in credit application, in: 2014 2nd International Conference on Information and Communication Technology (ICoICT). Presented at the 2014 2nd International Conference on Information and Communication Technology (ICoICT), IEEE, Bandung, Indonesia, pp. 84-89. https://doi.org/10.1109/ICoICT.2014.6914045

Indonesia, P.R., 1998. Undang-undang Republik Indonesia nomor 10 tahun 1998 tentang perubahan atas Undang-undang nomor 7 tahun 1992 tentang perbankan. BP. Cipta Jaya.

Jóhannsson, J., 2017. Detecting fraudulent users using behaviour analysis 66.

Kustina, K.T., 2018. MSMEs Credit Distribution and Non-Performing Loan towards Banking Companies Profit in Indonesia. Int. J. Soc. Sci. Humanit. IJSSH. https://doi.org/10.29332/ijssh.v2n1.72

Louppe, G., Wehenkel, L., Sutera, A., Geurts, P., 2013. Understanding variable importances in forests of randomized trees 9 .

$\mathrm{Xu}$, J., Chen, D., Chau, M., 2016. Identifying features for detecting fraudulent loan requests on P2P platforms, in: 2016 IEEE Conference on Intelligence and Security Informatics (ISI). Presented at the 2016 IEEE Conference on Intelligence and Security Informatics (ISI), IEEE, Tucson, AZ, USA, pp. 79-84. https://doi.org/10.1109/ISI.2016.7745447 